\title{
Analysis of Application of Plasma Ignition in Closed Vessel Tests
}

\author{
Radosław Trębiński *, Zbigniew Leciejewski (D), Zbigniew Surma (D) and Jakub Michalski (D) \\ Faculty of Mechatronics, Armament and Aerospace, Institute of Armament Technology, Military University of \\ Technology, 2 Gen. S. Kaliskiego Street, 00-908 Warsaw, Poland; zbigniew.leciejewski@wat.edu.pl (Z.L.); \\ zbigniew.surma@wat.edu.pl (Z.S.); jakub.michalski@wat.edu.pl (J.M.) \\ * Correspondence: radoslaw.trebinski@wat.edu.pl
}

Citation: Trębiński, R.; Leciejewski, Z.; Surma, Z.; Michalski, J. Analysis of Application of Plasma Ignition in Closed Vessel Tests. Energies 2021, 14, 6377. https://doi.org/10.3390/ en14196377

Academic Editor: Pascal Brault

Received: 9 September 2021

Accepted: 29 September 2021

Published: 6 October 2021

Publisher's Note: MDPI stays neutral with regard to jurisdictional claims in published maps and institutional affiliations.

Copyright: (c) 2021 by the authors. Licensee MDPI, Basel, Switzerland. This article is an open access article distributed under the terms and conditions of the Creative Commons Attribution (CC BY) license (https:// creativecommons.org/licenses/by/ $4.0 /)$.

\begin{abstract}
This paper presents the results of a comparative investigation into the effects of the ignition method on the ballistic properties of three types of propellants: a single-base propellant, a doublebase propellant and a low vulnerability (LOVA) propellant, as determined via closed vessel tests (CVT). Conventional gunpowder ignition and plasma jet ignition methods were used. The influence of the ignition method on the values of the propellant characteristics obtained in CVT was analysed. It was found that the method of ignition has an influence on the values of propellant characteristics, determined in CVT. An analysis of the experimental form functions showed that plasma ignition is not a solution to the problems inherent to the process of determining the ballistic properties of propellants in which the burning process deviates from the geometric burning law.
\end{abstract}

Keywords: closed vessel test; gun propellant; gunpowder ignition; plasma ignition

\section{Introduction}

Gunpowder ignition (GPI) is a popular method of ignition used in closed vessel tests (CVT). Its main drawback is the relatively long time required for the ignition energy delivery. The conventional black powder ignition method can be updated by applying new materials (e.g., [1-3]) or by applying other ignition systems such as the plasma jet or current injection [4-22] as well as laser ignition [23-28]. Plasma jet ignition (PJI) is characterised by the very short time required for energy delivery. This gives rise to an assumption that the simultaneous ignition of all grains of tested propellant are better fulfilled than in the case of GPI. This is an important assumption because methods of analysing CVT results are based upon it. Therefore, PJI is an interesting alternative to GPI. Analyses of the application of PJI in the literature were focused on the augmented combustion of propellants due to the electrical discharge and the compensation of the influence of ambient temperature, mainly from the point of view of application in electrothermal guns. High electrical energy values from 20 to $70 \mathrm{~kJ}$ were used.

In very few publications, low electrical energy ignition systems that can be applied as an alternative to conventional GPI in CVT were used. In [8], the effects of PJI with electrical energies from 2 to $4.6 \mathrm{~kJ}$ were compared with the effects of GPI for a single-base, a double-base and a LOVA propellant. A small closed vessel of $46 \mathrm{~cm}^{3}$ capacity was used. Measured pressure time courses were compared. The main observation was a spectacular acceleration of the ignition using PJI. In [17], the effects of applying GPI and PJI on the burning rate values were compared for a single-base propellant. Relatively high values of the electrical energy were applied, namely 20 and $40 \mathrm{~kJ}$, but a much larger closed vessel of $460 \mathrm{~cm}^{3}$ capacity was used. For the loading density value $150 \mathrm{~kg} / \mathrm{cm}^{3}$, the values of the burning rate were somewhat higher for PJI ignition, but for the loading density values 225 and $300 \mathrm{~kg} / \mathrm{m}^{3}$, they were similar. In [21], a vented closed vessel of $80 \mathrm{~cm}^{3}$ capacity was used for determining the ignition time of a single-base and a double-base propellant ignited by the use of GPI and PJI. Electrical energy values from 1.1 to $4 \mathrm{~kJ}$ were applied. A shortening of the ignition time from 1000 to $300 \mathrm{~ms}$ was observed. In [22], a comparison 
between the effects of GPI and PJI application in CVT for a single-base propellant was made. A closed vessel of $157 \mathrm{~cm}^{3}$ capacity was used, and an electrical energy of about $4 \mathrm{~kJ}$ was applied. The main findings are as follows: PJI shortens the ignition delay; however, this effect is distinct only for loading density values less than $150 \mathrm{~kg} / \mathrm{m}^{3}$. PJI increases the vivacity values in the first period of combustion; however, the scatter of the vivacity values is larger than for GPI.

This paper presents an extension of the analysis presented in [22]. In the paper, we look for an answer to the question: Is it worthwhile to replace the classical gunpowder ignition with the plasma jet ignition in closed vessel tests? The results of a comparative study on the respective effects of two ignition methods on the ballistic properties of a single-base propellant, a double-base propellant and a LOVA-type propellant are analysed. The initial parts of the pressure courses are compared, revealing the different characters in the ignition process. The influence of the method of ignition on the propellant force and the co-volume values, the burning rate values and the experimental shape function are analysed. Conclusions concerning the applicability of the plasma ignition method in closed vessel tests are formulated.

\section{Materials and Methods}

Closed vessel tests were performed for the two methods of ignition in the same closed vessel, with a capacity of $157 \mathrm{~cm}^{3}$. Two ignition plugs were used, and the ignition plug used for black powder ignition is shown in Figure 1. The gunpowder igniter with a mass from 1.4 to $1.5 \mathrm{~g}$ is enclosed in a plastic bag and ignited by a hot wire.

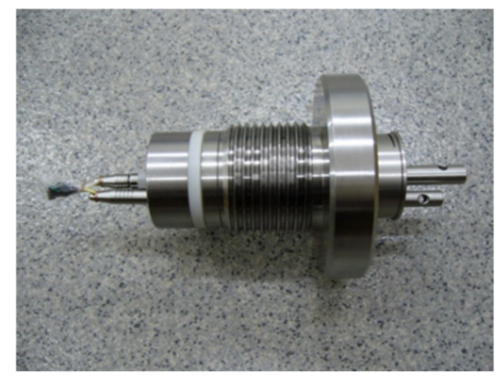

Figure 1. Ignition plug equipped with black powder igniter.

A drawing of the plug with the capillary plasma generator is shown in Figure 2. The plasma was generated as a result of the discharge of high-voltage capacitors through a small-diameter copper wire $(0.7 \mathrm{~mm})$ placed in a polyethylene tube. This wire rapidly evaporated, and the current flowing through the vapours of the copper-air mixture induced very strong ionisation of the gases and, eventually, formation of the plasma.

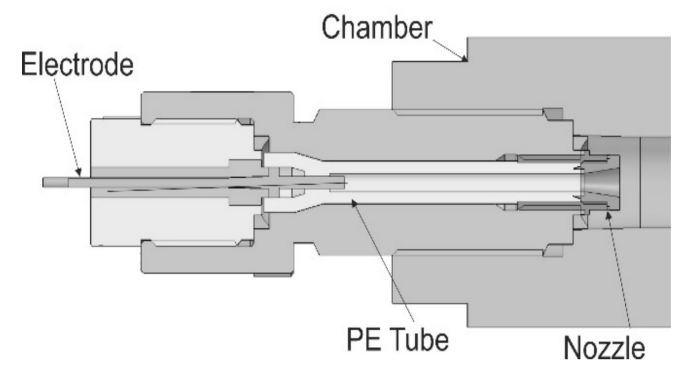

Figure 2. Ignition plug equipped with plasma generator (cross section).

All tests were conducted at ambient temperature. The pressure was measured using a HPI 5QP 6000M piezoelectric transducer, the signal of which was amplified by a TA-3/D amplifier and recorded on a Keithley DAS-50 12-bit analogue-to-digital converter at $1 \mathrm{MHz}$ frequency. The maximum systematic error of the indirect pressure measurement system was $1.1 \%$. 
Closed vessel tests were performed for three types of propellants. Their geometric characteristics are given in Table 1 . The tests were performed for the propellant mass: 15 , 22.5 and $30 \mathrm{~g}$. Therefore, the loading density values were $\Delta=100,150$ and $200 \mathrm{~kg} / \mathrm{m}^{3}$. One test was performed for a given $\Delta$. For one value of $\Delta$, the test was doubled in order to control repeatability of the measurement results. The mass of the gunpowder igniter was in the range of 1.4-1.5 g. It was adjusted to ensure that the nominal value of ignition pressure $3.16 \mathrm{MPa}$ was the same in all tests. In the case of the plasma ignition method, the same electrical energy $3.84 \mathrm{~kJ}$ was delivered; however, the values of the ignition pressure varied by approximately $20 \%$.

Table 1. Average dimensions of propellant grains.

\begin{tabular}{|c|c|c|c|c|c|c|}
\hline Propellant & Grain Shape & $\begin{array}{l}\text { Diameter } \\
{[\mathrm{mm}]}\end{array}$ & $\begin{array}{c}\frac{1}{2} \text { Web Size } \\
{[\mathrm{mm}]}\end{array}$ & $\begin{array}{l}\text { Perforation } \\
{[\mathrm{mm}]}\end{array}$ & Length $[\mathrm{mm}]$ & $\begin{array}{c}\text { Specific Surface } \\
\text { Area }[\mathrm{m} 2 / \mathrm{kg}]\end{array}$ \\
\hline $5 / 7 \mathrm{cfl}(\mathrm{SB})$ & 7-perforated & 2.58 & 0.255 & 0.180 & 6.20 & 1.86 \\
\hline JA-2 (DB) & 7-perforated & 8.78 & 0.893 & 0.546 & 14.15 & 0.52 \\
\hline SC (L) & 7-perforated & 6.30 & 0.570 & 0.580 & 8.70 & 0.84 \\
\hline
\end{tabular}

$\mathrm{SB}$, single-base (NC/other 95/5); DB, double-base (NC/NG/DENDG/other 58/16/25/1); and L, LOVA (RDX/NC/CAB/Triacetin/other $74 / 10 / 6 / 6 / 4)$.

Based on the maximum values of experimentally measured pressure, the propellant force $f$ and the co-volume $\eta$ values were calculated in accordance with STANAG 4115 [29]. In the case of plasma jet ignition, the height of the initial plateau of pressure was taken as the ignition pressure. However, it is not clear to what extent the copper vapour undergoes condensation at the moment, when the maximum value of pressure is attained. Therefore, the values of $f$ and $\eta$ were also calculated for the ignition pressure $p_{\text {ign }}$ equal to zero. The determined values of $f$ and $\eta$ are given in Table 2 (values in parenthesis correspond to $\left.p_{\text {ign }}=0\right)$.

Table 2. Propellant force $f$ and co-volume $\eta$.

\begin{tabular}{ccccc}
\hline Propellant & $f[\mathbf{k J} / \mathbf{k g}]$ (GPI) & $f[\mathbf{k J} / \mathbf{k g}]($ PLI) & $\eta\left[\mathbf{d m}^{3} / \mathbf{k g}\right](\mathbf{G P I})$ & $\eta\left[\mathbf{d m}^{3} / \mathbf{k g}\right]($ PLI) \\
\hline 5/7cfl (SB) & 811 & $806(834)$ & 1.544 & $1.612(1.531)$ \\
JA-2 (DB) & 919 & $853(862)$ & 1.307 & $1.508(1.518)$ \\
SC (L) & 882 & $843(859)$ & 1.574 & $1.654(1.629)$ \\
\hline
\end{tabular}

The values of the force $f$ are generally lower and the values of the co-volume $\eta$ are generally higher in the case of the plasma jet ignition. As a possible reason for these relations, one can consider an enhancement of the heat transfer to the closed vessel walls due to the presence of plasma. It may cause diminishing maximum values of pressure in the case of GPI.

In the analysis of CVT results, the idea of experimental shape function [30] is applied. It can be explained in the following way. The rate of change of the mass of an individual propellant grain $m_{g i}$ is given by the following equation:

$$
d m_{g i} / d t=\rho_{i} S_{g i} r_{i}
$$

where $p_{i}$ is the propellant grain density, $S_{g i}$ is the area of a burning surface and $r_{i}$ is the burning rate. Summing up for $n_{g}$ grains, included in the propellant charge, we obtain the following:

$$
d m / d t=\sum_{i=1}^{n_{g}} \rho_{i} S_{g i} r_{i}
$$


where $m$ means the mass of the propellant charge. Assuming that all grains have the same density $p$ and they burn at the same rate $r$, we can represent Equation (2) in the form:

$$
d m / d t=\rho r \sum_{i=1}^{n_{g}} S_{g i}
$$

Dividing both sides of Equation (3) by the initial mass of propellant charge $n_{g} p V_{g 0}$, we obtain the following:

$$
d z / d t=\left(\rho r \sum_{i=1}^{n_{g}} S_{g i}\right) /\left(n_{g} \rho V_{g 0}\right)
$$

where $z$ is the relative burned mass of the propellant charge and $V_{g 0}$ is the initial volume of a propellant grain. Let us represent Equation (4) in the following form:

$$
d z / d t=S_{g 0} / V_{g 0} r\left[\sum_{i=1}^{n_{g}}\left(S_{g i} / S_{g 0}\right)\right] / n_{g}
$$

Relative burning surface $S_{g i} / S_{g 0}$ is a function of the relative burnt mass of a propellant grain $z_{i}$ and is determined by the shape of the grain. That is why it is called "shape function" $\phi\left(z_{i}\right)[31]$. We defined the function as follows:

$$
\phi_{e x}(z)=\sum_{i=1}^{n_{g}} \phi\left(z_{i}\right) / n_{g}
$$

where all grains are ignited at the same time $z_{i}=z$ and $\phi_{e x}(z)$ is identical to $\phi(z)$. However, when grains are ignited gradually, $\phi_{e x}(z)$ is an average shape function. It depends not only on the shape of grains but also on the details of the ignition process. Moreover, if some grains are crushed, functions $\phi\left(z_{i}\right)$ change. These changes affect the function $\phi_{e x}(z)$. That is why the function is a useful tool for analysing peculiarities of the propellant burning process. The function can be determined based on the results of CVT. Therefore, we call it the "experimental shape function". The following formulae are used for calculations of $d z / d t$ values:

$$
\begin{aligned}
& d z / d t=(d z / d p)(d p / d t) \\
& z=b_{1} p_{s} /\left(f+b_{2} p_{s}\right), \quad p_{s}=p-p_{\text {ign }}, \quad b_{1}=1 / \Delta-1 / \rho, \quad b_{2}=\eta-1 / \rho \\
& d z / d p=\left(b_{1} f\right) /\left(f+b_{2} p_{s}\right)^{2}
\end{aligned}
$$

where $p$ is the measured pressure, $p_{\text {ign }}$ is the ignition pressure, $\Delta$ is the loading density and $\eta$ is the co-volume.

Burning rate dependence on the pressure value is approximated by Vielle's law:

$$
r=\beta p^{n}
$$

Combing Equations (5), (6) and (10), we obtain the following:

$$
d z / d t=\beta S_{g 0} / V_{g 0} \phi_{e x}(z) p^{n}
$$

We introduce the following function:

$$
G(z)=\theta \phi_{e x}(z), \quad \theta=\beta S_{g 0} / V_{g 0} p_{0}^{n-1}, \quad p_{0}=0.1 \mathrm{MPa}
$$

Taking into account Equation (11), we have the following:

$$
G(z)=(d z / d t) /\left(p_{0} x^{n}\right), \quad x=p / p_{0}
$$


The value of the exponent $n$ can be determined from the following relation:

$$
\log _{10}(d z / d t)=\log _{10}\left[p_{0} G(z)\right]+n \log _{10} x
$$

By calculating the $d z / d t$ values for several values of the loading density and the same value of $z$, we can treat Equation (14) as a linear relation between $\log _{10}(d z / d t)$ values and $\log _{10} x$ values. The slope determines the value of $n$; thus, the $n$ values for $z=0.3,0.4,0.5$, 0.6 and 0.7 are determined, and then, the average value is calculated. Knowing this value, we calculate values of $G(z)$.

The value of the coefficient $\theta$ is determined by minimising the following measure of the difference between the experimental shape function and the theoretical shape function:

$$
I(\theta)=\sum_{j=1}^{n}\left[G\left(z_{j}\right)-\theta \phi\left(z_{j}\right)\right]^{2}
$$

The following formula for calculation of $\theta$ value is obtained:

$$
\theta=\left[\sum_{j=1}^{n} G\left(z_{j}\right) \phi\left(z_{j}\right)\right] / \sum_{i=1}^{n} \phi\left(z_{j}\right)^{2}
$$

Values of $G(z)$ and $\phi(z)$ are taken for $z_{j} \in[0.3 ; 0.7]$, so only the central part of the $G(z)$ function is taken into account. In this way, an influence of the ignition phase and the last phase of propellant combustion is eliminated.

In the last step, we calculate values of the experimental shape function:

$$
\phi_{e x}(z)=G(z) / \theta
$$

\section{Results and Discussion}

The initial pressure records obtained for the two ignition methods are presented in Figure 3. A significant difference between the ignition processes for the two methods can be inferred from these records.

As shown in [32], ignition by gunpowder takes place at a pressure value that is much lower than the nominal ignition pressure; Figure 1 shows the pressure courses that illustrate this fact. If burning of a tested propellant was initiated after full combustion of the gunpowder igniter, pressure courses up to the nominal value of ignition pressure would coincide. However, they diverge starting from approximately $0.1 \mathrm{MPa}$. This means that a parallel burning of gunpowder and a tested propellant takes place, starting at a pressure value that is much lower than the nominal value and ending at a pressure value considerably higher than the nominal value. This effect complicates determining the burning rate of a tested propellant for low pressure values.

This problem is not present in the case of plasma jet ignition. The beginning of burning of a tested propellant can be determined, quite precisely, as the moment at which pressure starts to increase after a period of approximately constant pressure. Such a plateau was not observed in [8], probably due to the low capacity of the closed chamber $\left(46 \mathrm{~cm}^{3}\right)$. The low capacity means that the plasma generator is closer to the ignited propellant charge. Therefore, ignition can start sooner.

Pressure courses after the plateau reflect the process of burning a tested propellant. However, one can expect that the process of condensation of copper vapour may affect the pressure course. The relatively long period of constant pressure values may suggest that the process of condensation is relatively slow, and it does not affect the pressure course until the moment the maximum pressure value is attained. It must also be taken into account that the boiling point of copper $(2865 \mathrm{~K})$ is close to the values of the propellant flame temperature. Therefore, it is probable that copper remains as a vapour during the whole combustion cycle. 

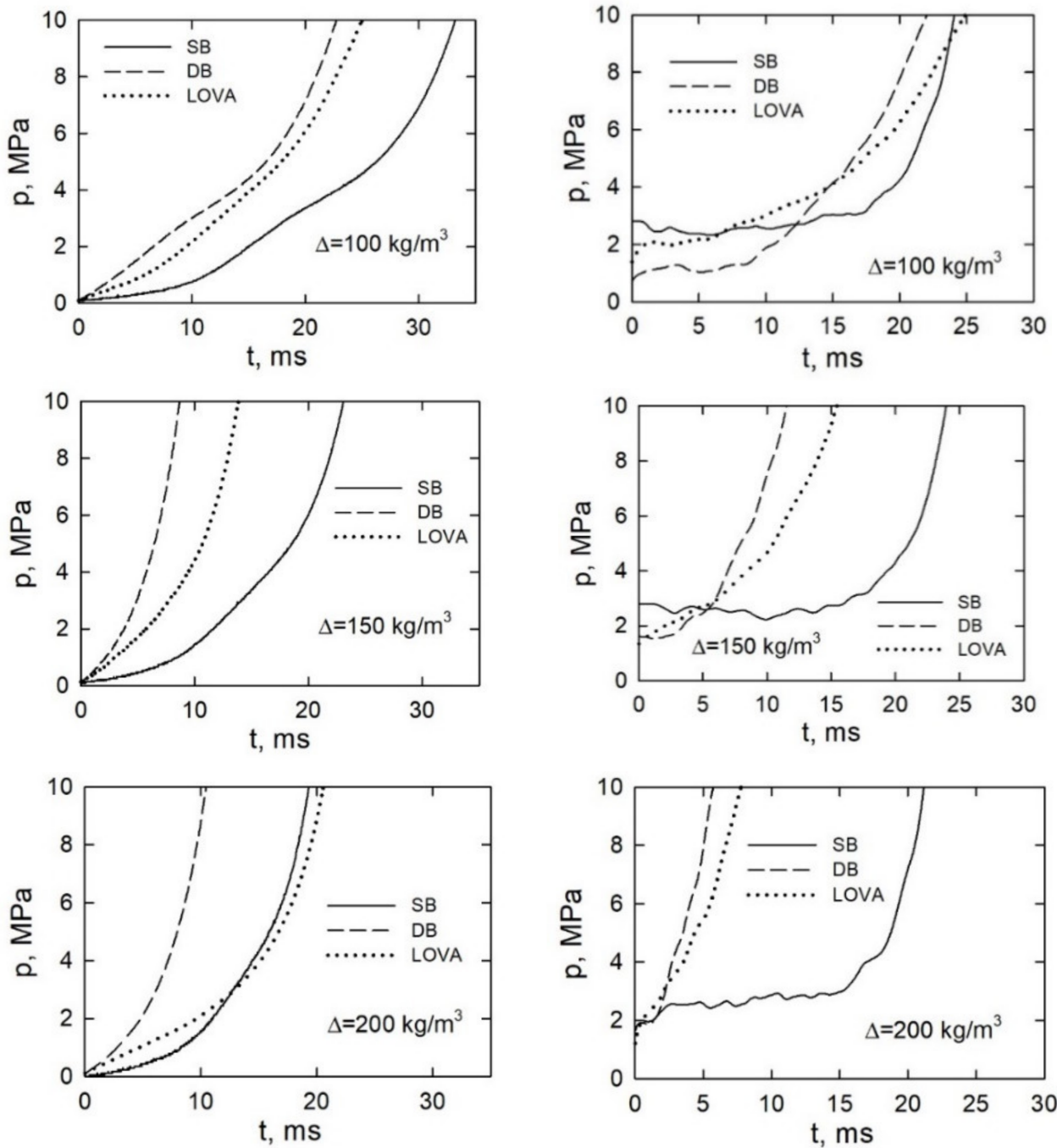

Figure 3. Initial parts of the pressure courses for gunpowder ignition (left) and plasma jet ignition (right).

Initial parts of the pressure courses for the plasma jet ignition have an interesting feature. In the case of the double-base propellant and the LOVA propellant, the increase of loading density shortens the ignition time and increases the rate of pressure rise. The increase in loading density increases the number of propellant grains that are ignited at almost the same time. A larger number of burning grains means faster gas production and, hence, a faster pressure rise. This, in turn, accelerates the burning process. This effect is not observed in the case of ignition of the single-base propellant. It can be explained by the large value of the specific surface area $A_{S}$ of this propellant (see Table 1). It is 3.7 times larger than the $A_{S}$ of the JA-2 propellant and 2.2 times larger than the $A_{S}$ of the SC propellant. This means that considerably more energy is necessary to heat $5 / 7 \mathrm{cfl}$ propellant grains to the ignition temperature. The discharge energy is sufficient to ignite all JA-2 and SC grains, but it is insufficient to ignite all of the $5 / 7 \mathrm{cfl}$ propellant grains. As a consequence, approximately the same mass of $5 / 7$ propellant is ignited for all values of loading density. That is why pressure courses for different values of loading density are close to each other.

The limited ignition energy ( 0.13 to $0.28 \mathrm{~kJ} / \mathrm{g}$ ) has a weaker influence in the case of the gunpowder ignition. Due to contact between burning gunpowder grains and liquid potassium salt droplets, some of the tested propellant grains are ignited (30\% of gunpowder combustion products have a liquid form, and liquid content increases at cooling to 55\% [33]). Gases, produced by the burning of these grains, screen the remaining part of the propellant bed from the action of gunpowder combustion products. The grains of this part of the bed 
are heated by these gases. This causes the energy of the igniter, flame temperature, ignition temperature and burning rate to influence the ignition process. Therefore, the size of the propellant grains has a weaker influence on the pressure courses in the first phase of the burning process.

The values of the exponent $n$ and the coefficient $\beta$ are given in Table 3 . Plots of the dependence of the burning rate on pressure value are shown in Figure 4, and they suggest that the method of ignition influences burning rate; however, this influence is relatively weak. A similar observation was made in [17]. It should be underscored that the method used in this work for determining the burning rate differs from that used in [17].

Table 3. The values of the exponent $n$ and the coefficient $\beta$.

\begin{tabular}{ccccc}
\hline Propellant & $\boldsymbol{n}$ (PLI) & $\boldsymbol{n}$ (GPI) & $\boldsymbol{\beta}$ (PLI) & $\boldsymbol{\beta}$ (GPI) \\
\hline 5/7 cfl (SB) & $0.91 \pm 0.15$ & $0.93 \pm 0.10$ & $0.100 \pm 0.004$ & $0.096 \pm 0.003$ \\
JA-2 (DB) & $0.85 \pm 0.04$ & $0.86 \pm 0.09$ & $0.228 \pm 0.006$ & $0.228 \pm 0.006$ \\
SC (L) & $0.98 \pm 0.19$ & $0.99 \pm 0.11$ & $0.057 \pm 0.003$ & $0.055 \pm 0.004$ \\
\hline
\end{tabular}

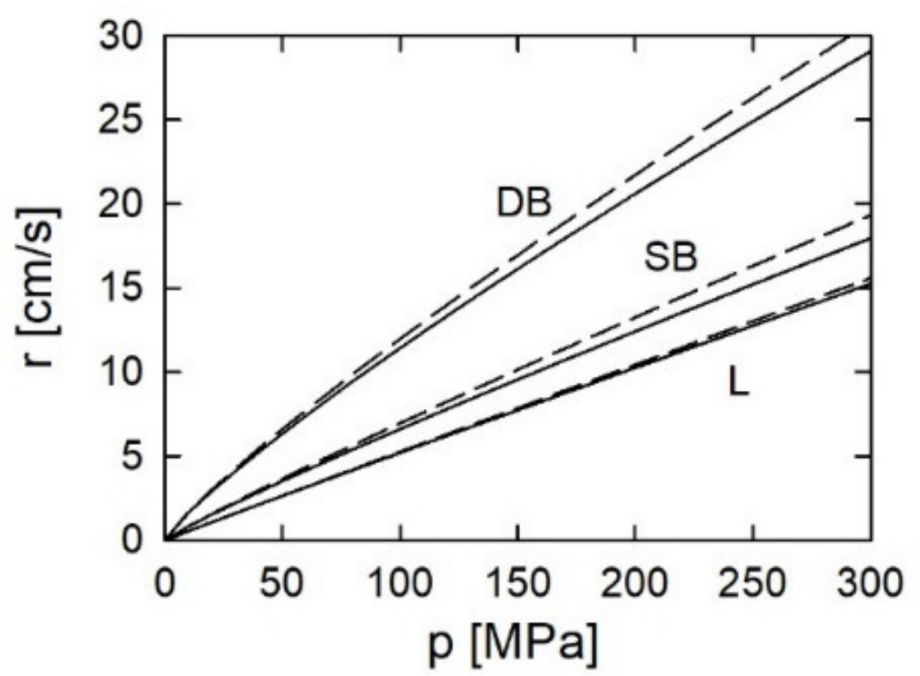

Figure 4. Plots of dependence of burning rate on pressure: solid lines plasma jet ignition, dashed lines-gunpowder ignition.

Plots of theoretical and experimental shape functions are shown in Figure 5. Only in the case of the $5 / 7 \mathrm{cfl}$ propellant is there a distinct difference between shape functions determined for the two methods of ignition. Due to the faster ignition by plasma jet, the area of the burning surface attains its maximum value quicker than in the case of gunpowder ignition. In the case of propellants with larger grains, this effect is weaker. In further phases of the burning process, differences between shape functions determined for different methods of ignition become small. This corroborates the hypothesis that differences between theoretical and experimental shape functions cannot be attributed only to the influence of ignition. As shown in [34], they may have a relationship with the mechanical properties of the propellants. Grains of single-base and LOVA propellants have a tendency to brittle crush, which increases the burning surface in the first phase of burning and diminishes it in the second phase. 

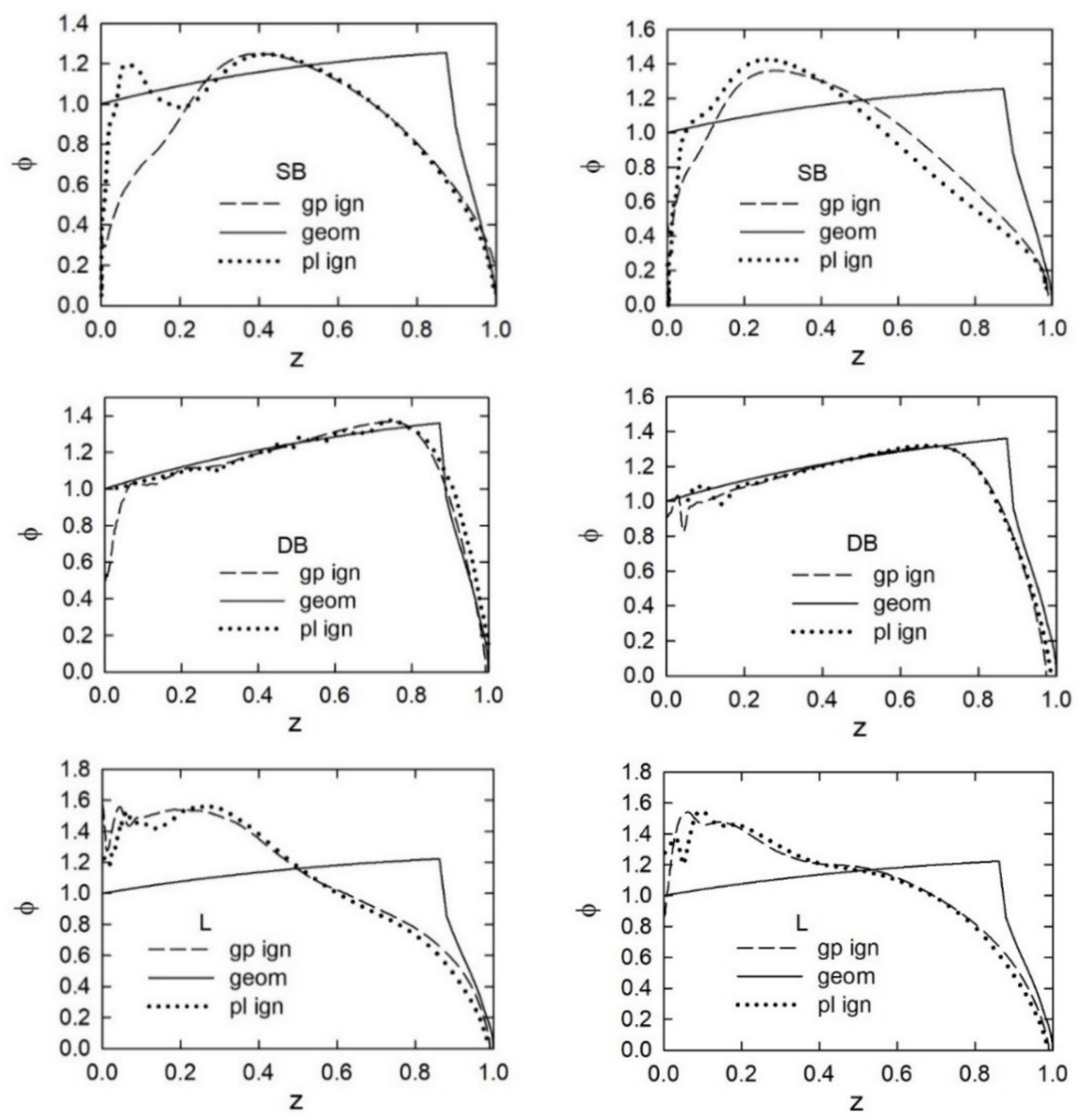

Figure 5. Plots of theoretical (geometrical) and experimental shape functions, where $\Delta=100 \mathrm{~kg} / \mathrm{m}^{3}$ (left) and $\Delta=200 \mathrm{~kg} / \mathrm{m}^{3}$ (right).

\section{Conclusions}

(1) The results from the analysis suggest that propellant characteristics determined in closed vessel tests for gunpowder ignition and plasma jet ignition differ. However, the differences are not large.

(2) The application of plasma jet ignition is recommended for determining the burning rate at low values of pressure. In the case of gunpowder ignition, parallel burning of the gunpowder and a tested propellant considerably influences the rate.

(3) Discharge energy should be fitted to the tested propellant. Higher values of the energy are necessary in the case of fine grains.

(4) Contrary to expectations, the use of plasma jet ignition does not eliminate differences between the theoretical and experimental shape function for single-base and LOVA propellants. This proves that the differences cannot be explained by the influence of the ignition.

Author Contributions: Conceptualisation, Z.L. and R.T.; methodology, Z.L. and R.T.; software, R.T.; validation, Z.L. and Z.S.; formal analysis, Z.L., J.M. and R.T.; investigation, Z.S. and J.M.; resources, Z.L. and Z.S.; data curation, R.T.; writing-original draft preparation, Z.L. and R.T.; writing—review and editing, Z.L., J.M. and Z.S.; visualisation, J.M. and R.T.; supervision, Z.L.; project administration, Z.L.; funding acquisition, Z.L. and R.T. All authors have read and agreed to the published version of the manuscript.

Funding: This research was funded by the Ministry of Defence of Poland, grant number GBMON/13988/2018/WAT.

Institutional Review Board Statement: Not applicable. 
Informed Consent Statement: Not applicable.

Data Availability Statement: Not applicable.

Conflicts of Interest: The authors declare no conflict of interest.

\section{References}

1. Van Driel, C.A. Ignition Behaviour of LOVA Propellant. In Proceedings of the 24th International Symposium on Ballistics, New Orleans, LA, USA, 22-26 September 2008; pp. 258-264.

2. Baschung, B.; Bouchama, A.; Comet, M.; Boulnois, C. Experimental Investigation of Different Ignition Methods for LOVA Gun Propellant. In Proceedings of the 28th International Symposium on Ballistics, Atlanta, GA, USA, 22-26 September 2014; pp. 532-541.

3. Boulnois, C.; Baschung, B.; Bouchama, A.; Comet, M.; Mura, D.; Steinbach, C. Experimental Characterization of the Energy Transferred from an Igniter Based on Nanothermites to the Propellant Bed. In Proceedings of the 27th International Symposium on Ballistics, Freiburg, Germany, 22-26 April 2013; pp. 38-49.

4. Bach, A.; Eisenreich, N.; Neiger, M. Charakterisierung eines Plasma-Jets mit optischen und spektroskopischen Methoden. In Proceedings of the 22nd International Annual Conference of ICT, Karlsruhe, Germany, 2-5 July 1991; pp. 1-10.

5. Powell, J.D.; Zielinski, A.E. Capillary Discharge in the Electrothermal Gun. IEEE Trans. Magn. 1993, 29, 591-596. [CrossRef]

6. Woodley, C.R.; Fuller, S. Apparent Enhanced Burn Rates of Solid Propellants Due to Plasmas. In Proceedings of the 16th International Symposium on Ballistics, San Francisco, CA, USA, 23-27 September 1996; pp. 153-162.

7. Proud, W.G.; Bourne, N.K. The Electrothermal Enhancement of Propellant Burning by Plasma Injection. Propellants, Explos. Pyrotech. 1997, 22, 212-217. [CrossRef]

8. Grune, D.; Hensel, D. Combustion Behaviour of LOVA-Solid-Propellant by Ignition with Hot Plasma Gases and its Influence on the Interior Ballistic Cycle. In Proceedings of the 17th International Symposium on Ballistics, Midrand, South Africa, 23-27 March 1998; pp. 359-366.

9. Oberle, W.F.; Wren, G.P. Radiative and Convective Heat Loss in Electrothermal-Chemical (ETC) Closed Chambers. In Proceedings of the 35th JANNAF Combustion Subcommittee Meeting, Tucson, AZ, USA, 7-11 December 1998; pp. 229-236.

10. Woodley, C.R.; Saveli, G.E. Modelling Enhanced Gas Generation Rates in a $155 \mathrm{~mm}$ ETC Gun. In Proceedings of the 18th International Symposium on Ballistics, San Antonio, TX, USA, 15-19 November 1999; pp. 285-292.

11. Kooker, D.E. A Mechanism for TEC-Augmented Burning Rate of Solid Propellant Consistient with Closed Chamber Experiments. In Proceedings of the 18th International Symposium on Ballistics, San Antonio, TX, USA, 15-19 November 1999; pp. $236-243$.

12. Powell, J.D.; Thornhill, L.; Batteh, J.H.; Verdon, M. Current distribution and resistance characteristics in plasma injectors for electrothermal-chemical launch. IEEE Trans. Magn. 1999, 35, 218-223. [CrossRef]

13. Birk, A.; Del Guercio, M.; Kinkennon, A.; Kooker, D.E.; Kaste, P.J. Interrupted-Burning Tests of Plasma-Ignited JA2 and M30 Grains in a Closed Chamber. Propellants Explos. Pyrotech. 2000, 25, 133-142. [CrossRef]

14. Taylor, M.J.; Woodley, C.R. Variation in Enhanced Gas Generation Rates in Electrothemal-Chemical Closed Chamber Studies. In Proceedings of the 19th International Symposium on Ballistics, Interlaken, Switzerland, 7-11 May 2001; pp. 179-186.

15. Lombard, J.M.; Baschung, B.; Grune, D.; Carriere, A.; Andre, P. Analysis of ETC or Classical Manometric Closed vessel tests with Coupling of Thermodynamic Equilibrium Calculations: Combustion Rates, Energy Losses. In Proceedings of the 19th International Symposium on Ballistics, Interlaken, Switzerland, 7-11 May 2001; pp. 171-178.

16. Koleczko, A.; Ehrhardt, W.; Schmid, H.; Kelzenberg, S.; Eisenreich, N. Plasma Ignition and Combustion. In Proceedings of the 19th International Symposium on Ballistics, Interlaken, Switzerland, 7-11 May 2001; pp. 195-202.

17. Lombard, J.M.; Baschung, B.; Carrière, A.; André, P. Modelling of Classical and ETC Manometric Closed Vessel Tests. In Proceedings of the 34th International Conference of Institute Chemistry Technology, Pfinztal, Germany; 2003.

18. Beyer, R.A.; Pesce-Rodriguez, R.A. The Response of Propellants to Plasma Radiation. IEEE Trans. Magn. 2005, 41, 344-349. [CrossRef]

19. Akahoshi, Y.; Kitagawa, J.; Koura, T.; Fukushige, S.; Tadaoka, M. Development and Evaluation of a TSLGG-Application of an ETC Gun System to its First Stage. IEEE Trans. Magn. 2006, 43, 279-283. [CrossRef]

20. Porwitzky, A.J.; Keidar, M.; Boyd, I.D. On the Mechanism of Energy Transfer in the Plasma-Propellant Interaction. Propellants, Explos. Pyrotech. 2007, 32, 385-391. [CrossRef]

21. Xiao, Z.; Xue, A.; Ying, S.; He, W.; Xu, F.; Hou, B. Experimental Studies of Propellant Loading Parameters and Plasma Flow-Field Interactions. IEEE Trans. Magn. 2009, 45, 514-517. [CrossRef]

22. Trebinski, R.; Leciejewski, Z.; Surma, Z.; Michalski, J. Comparative Analysis of Effects of Gunpowder and Plasma Ignitions in Closed Vessel Tests. Def. Technol. 2019, 15, 668-673. [CrossRef]

23. Brish, A.A.; Galeev, I.A.; Zaitsev, B.N.; Sbitnev, E.A.; Tatarintsev, L.V. Mechanism of initiation of condensed explosives by laser radiation. Combust. Explos. Shock. Waves 1969, 5, 326-328. [CrossRef]

24. Austin, W.; Barrows, A.W.; Forch, B.E.; Richard, A.; Beyer, R.A.; Cohen, A.; Newberry, J.E. Laser Ignition in Guns, Howitzers and Tanks: The LIGHT Program; Report ARL-TR-62; US Army Research Laboratory, Aberdeen Proving Ground: Aberdeen, MD, USA, 1993. 
25. Beyer, R.A.; Hirlinger, J.M. Laser Ignition in a Medium-Caliber Gun: A Study of Igniter Influence on Action Time; Report ARL-TR-1864; US Army Research Laboratory, Aberdeen Proving Ground: Aberdeen, MD, USA, 1999.

26. Herreros, D.N.; Fang, X. Laser ignition of elastomer-modified cast double-base (EMCDB) propellant using a diode laser. Opt. Laser Technol. 2017, 89, 21-26. [CrossRef]

27. Churchyard, S.; Fang, X.; Vrcelj, R. Laser ignitibility of energetic crystals doped with gold nanoparticles. Opt. Laser Technol. 2019, 113, 281-288. [CrossRef]

28. Courty, L.; Gillard, P.; Ehrhardt, J.; Baschung, B. Experimental determination of ignition and combustion characteristics of insensitive gun propellants based on RDX and nitrocellulose. Combust. Flame 2021, 229, 111402. [CrossRef]

29. North Atlantic Council. STANAG 4115: Definition and Determination of Ballistic Properties of Gun Propellants, 2nd ed.; Military Agency for Standardization: Brussels, Belgium, 1997.

30. Trebinski, R.; Leciejewski, Z.; Surma, Z. Modifications of the Closed Vessel Test Results Analysis Method. In Proceedings of the 31st International Symposium on Ballistics, Hyderabad, India, 4-7 November 2019.

31. Carlucci, D.E.; Jacobson, S.S. Ballistics. Theory and Design of Guns and Ammunition; CRC Press: Boca Raton, FL, USA; London, UK; New York, NY, USA, 2008.

32. Trębiński, R.; Leciejewski, Z.; Surma, Z. Investigations of the Influence of Ignition on the Dynamic Vivacity of Propellants. Probl. Mechatron. Armament Aviat. Saf. Eng. 2019, 9, 1-14. [CrossRef]

33. Blackwood, J.D.; Bowden, F.P. The initiation, burning and thermal decomposition of gunpowder. Proc. R. Soc. Lond. Ser. A Math. Phys. Sci. 1952, 213, 285-306.

34. Trębiński, R.; Janiszewski, J.; Leciejewski, Z.; Surma, Z.; Kamińska, K. On Influence of Mechanical Properties of Gun Propellants on Their Ballistic Characteristics Determined in Closed Vessel Tests. Materials 2020, 13, 3243. [CrossRef] [PubMed] 